\title{
Fatou Diome, Inassouvies nos vies
}

\section{Carminella Biondi}

\section{(2) OpenEdition}

\section{Journals}

\section{Edizione digitale}

URL: http://journals.openedition.org/studifrancesi/6130

DOI: ERREUR PDO dans /localdata/www-bin/Core/Core/Db/Db.class.php L.34 : SQLSTATE[HY000]

[2006] MySQL server has gone away

ISSN: 2421-5856

\section{Editore}

Rosenberg \& Sellier

\section{Edizione cartacea}

Data di pubblicazione: 1 mai 2011

Paginazione: $224-225$

ISSN: 0039-2944

\section{Notizia bibliografica digitale}

Carminella Biondi, «Fatou Diome, Inassouvies nos vies», Studi Francesi [Online], 163 (LV | I) | 2011, online dal 30 novembre 2015, consultato il 07 janvier 2021. URL: http://journals.openedition.org/ studifrancesi/6130 ; DOI: https://doi.org/ERREUR PDO dans /localdata/www-bin/Core/Core/Db/ Db.class.php L.34 : SQLSTATE[HY000] [2006] MySQL server has gone away

Questo documento è stato generato automaticamente il 7 janvier 2021.

\section{c) () $९$}

Studi Francesi è distribuita con Licenza Creative Commons Attribuzione - Non commerciale - Non opere derivate 4.0 Internazionale. 


\title{
Fatou Diome, Inassouvies nos vies
}

\author{
Carminella Biondi
}

\section{NOTIZIA}

FATOU DIOME, Inassouvies nos vies, Paris, Éditions J’ai lu, 2010, pp. 253.

1 Si tratta della ristampa, in edizione tascabile, di un romanzo pubblicato da Flammarion nel 2008. L'etichetta romanzo, come capita spesso per le scritture contemporanee, in particolare per le scritture cosiddette postcoloniali è riduttiva, perché l'opera di Fatou Diome è ad un tempo un racconto coinvolgente sul piano narrativo ed una lunga riflessione sulla vita, che viene portata avanti attraverso le storie di alcuni personaggi, convocati dalla narratrice, Betty, detta la Loupe a causa della sua sete di osservare la vita delle persone che le stanno attorno. Questa attenzione quasi morbosa, nata, come capiremo negli ultimi capitoli, dalla sua incapacità di vivere la vita in prima persona a causa di un trauma infantile, le permette di entrare a poco a poco nella vita degli altri e di disegnare figure di uomini e, soprattutto, di donne che si impongono per la loro forza e la loro credibilità. Seguendo il percorso della giovane Betty, venuta dal Senegal a Strasburgo, dove il suo impegno resta piuttosto nebuloso (forse è scrittrice), si assiste al progressivo farsi e disfarsi di storie che ricostruiscono a poco a poco un mondo, o meglio le varie sfaccettature della vita umana, che spesso si diverte a dare agli eventi svolte inattese, felici o drammatiche.

2 Alcuni personaggi sono tracciati a tinte forti, ironiche, utilizzate, almeno agli inizi, per sottolineare una presa di distanza, per non dire una profonda antipatia della narratrice, antipatia che si stempera alla fine in una sorta di pietas per ogni vita evocata, una vita «inassouvie», come dice il titolo e come viene ripetuto spesso, in una sorta di refrain, soprattutto alla fine di ogni capitolo (il romanzo si compone di diciassette capitoli seguiti da un «Épilogue», che racconta in maniera del tutto inattesa e piuttosto criptica la scelta di vivere della narratrice): «Inassouvi, notre besoin de durer et de faire durer les liens. Inassouvi, notre besoin de préserver ceux que nous aimons. Inassouvis, nous survivons. Inconsolables, nous demeurons» (p. 236). Uno dei personaggi che subisce 
questo trattamento graffiante è la "prof de lettres [...] intello-écolo-bio», che capisce tutto con grande lucidità, fatta eccezione «des rapports humains» (p. 120), con inevitabili ripercussioni negative sulla realizzazione della propria vita, che si accomoda, alla fine, al «tran-tran des jours». Ma le pagine più belle, più partecipate del romanzo, con momenti di vero coinvolgimento emotivo, sono quelle dedicate a Félicité e, in generale, alla vecchiaia, accostata attraverso le visite della narratrice alla casa di riposo per anziani dove la vecchia amica è stata rinchiusa da parenti lontani ed avidi. Il refrain che conclude uno dei capitoli dedicati alle visite a Félicité e al racconto degli anziani di cui Betty ha deciso di trascrivere i ricordi, fissa in maniera incisiva la nostra impotenza a capire fino in fondo le vite degli altri (nonché la nostra stessa vita, come diranno altri capitoli), ma anche la capacità della scrittrice di spingersi, in questa ricerca, fin dove è umanamente possibile: «Inassouvi, le besoin de soulager les aînés, ils portent tant de morts dans leur mémoire!» (p. 96). Nonostante l'ampio spazio occupato dalle riflessioni personali sulla vita da parte della narratrice, riflessioni che e a volte appesantiscono un po' la pagina e sfiorano l'ovvietà, queste «vies inassouvies» appagano le attese del lettore. 